\title{
COMPORTAMENTO DE SEMENTES DE Copaifera multijuga DURANTE O ARMAZENAMENTO
}

\author{
Lucinda Carneiro GARCIA ${ }^{1}$, Divania de LIMA ${ }^{1}$
}

\begin{abstract}
RESUMO - O objetivo deste trabalho foi estudar o comportamento de sementes de Copaifera multijuga Hayne, sob diferentes condições de armazenamento visando estabelecer critérios para a conservação desse material por um maior periodo de tempo. Sementes frescas foram acondicionadas em saco de papel (embalagem permeável) e vidro (embalagem impermeável), e armazenadas em ambiente de laboratório (temperatura média $27^{\circ} \mathrm{C}$ e umidade relativa $85 \%$ ) e câmara fria (temperatura de $8^{\circ} \mathrm{C}$ e umidade relativa $55 \%$ ) durante seis meses. O delineamento adotado foi o inteiramente casualizado, em esquema fatorial $2 \times 2 \times 3$ (embalagem, ambiente, período), com quatro repetições de 25 sementes. A qualidade das sementes foi avaliada bimestralmente, por meio dos parâmetros: teor de água, germinação, índice de velocidade de emergência e comprimento de plântula. A percentagem de germinação inicial das sementes foi $94 \%$ e a umidade $34 \%$. Sementes de Copaifera multijuga tiveram sua viabilidade reduzida para $75 \%$ e $45 \%$, em embalagem permeável e impermeável, respectivamente, após dois meses de armazenamento em ambiente de laboratório. A embalagem permeável mostrou-se eficiente na conservação de sementes desta espécie quando mantidas em câmara fria, com percentagem de germinação de $85 \%$, por um período de quatro meses.
\end{abstract}

Palavras-chave: sementes florestais, embalagem, viabilidade, germinação.

\section{Storage Behaviour of Copaifera multijuga Seeds}

ABSTRACT - In this study, the effect of different storage conditions on the behaviour of Copaifera multijuga Hayne seeds was evaluated in order to determine the criterion for its conservation during a long period. Fresh seeds were enclosed in paper bags (permeable packing) or glass bottles (not permeable packing), and stored in laboratory environment $\left(27^{\circ} \mathrm{C}\right.$ average temperature and $85 \%$ relative humidity) and in a cold cabinet $\left(8{ }^{\circ} \mathrm{C}\right.$ temperature and $55 \%$ relative humidity),during six months. A randomized design was adapted, with a factorial scheme $2 \times 2 \times$ 3 (packing method, environment, storage duration), with four replications. The quality of the seeds was evaluated bimonthly through the parameters: water content, germination, emergence speed rate and seedling length. The initial percentage of germination was $94 \%$ and the water content, $34 \%$. The viability of the seeds was reduced to $75 \%$ and $45 \%$, respectively, in permeable and not permeable packing, after two months of storage in the laboratory environment. The permeable packing in the cold cabinet was found to be efficient for the conservation of the seeds of this species, with $85 \%$ percentage of germination, after a storage 4 months.

Key-words: forest seed, packaging, viability, germination.

\section{INTRODUÇÃO}

O processo de aproveitamento seletivo das espécies madeireiras da Amazônia tem se intensificado nos últimos anos. A devastação decorrente da exploração desordenada dessas espécies induz uma intensificação dos estudos sobre as condições de conservação das sementes, visando garantir o fornecimento desse insumo aos programas de reflorestamento e reposição florestal.

A copaiba (Copaifera multijuga Hayne) é uma espécie arbórea da familia Leguminosae, subfamília

\footnotetext{
'Embrapa Amazônia Ocidental. Caixa Postal. 319. 69.011-970, Manaus, Amazonas, Brasil.
} 
Caesalpinioideae, que ocorre abundantemente em toda a Amazônia brasileira. É uma árvore de grande porte, podendo atingir mais de $30 \mathrm{~m}$ de altura e diâmetro em torno de 50 $\mathrm{cm}$. A sua madeira é muito utilizada nas serrarias da região, para a confecção de compensados e laminados (Hurmel et al.1994). Essa espécie tem como característica a produção de óleo no fuste, muito utilizado na medicina como um antinflamatório (Albuquerque, 1989; Parrotta et al., 1995).

A conservação de sementes de essências florestais é de fundamental importância quando se visa o desenvolvimento de programas silviculturais (Leão, 1984). Entretanto, nas regiões tropicais a predominância de temperatura e umidade relativa do ar elevadas, são condições extremamente desfavoráveis para a manutenção da qualidade fisiológica das sementes, sendo o armazenamento sob baixa temperatura uma das alternativas utilizadas na conservação das sementes de espécies arbóreas (Leão, 1984; Popinigis, 1985; Façanha \& Varela, 1986/87).

Com relação ao estudo das sementes de $C$. multijuga, a literatura é escassa. Loureiro et al. (1979) afirmam que a percentagem de germinação das sementes é de $69 \%$. Alencar (1981) concluiu que as sementes apresentavam em média $87,5 \%$ de germinação, percentagem esta considerada alta pelo referido autor. Embrapa (1991) relata que a percentagem de germinação de sementes desta espécie, na região do Tapajós, é de $82 \%$. Façanha \& Varela (1986/87) constataram que as sementes de $C$. multijuga, após 30 dias de armazenamento em latas de alumínio fechadas, em ambiente de laboratório, sofreram uma redução média de $35 \%$ na percentagem de germinação que inicialmente era de $91 \%$.

O objetivo deste trabalho foi estudar o comportamento de sementes de C. multijuga sob diferentes condições de armazenamento, visando estabelecer critérios para a conservação desse material por um maior período de tempo.

\section{MATERIAL E MÉTODOS}

As sementes utilizadas neste estudo foram coletadas de árvoresmatrizes de $C$. multijuga localizadas na área experimental da Embrapa Amazônia Ocidental, Manaus - AM.

$\mathrm{O}$ experimento foi conduzido no Laboratório de Análise de Sementes da Embrapa Amazônia Ocidental, onde foram avaliados os efeitos de embalagem, ambiente e período de armazenamento sobre a conservação da qualidade das sementes. O delineamento empregado foi o inteiramente casualizado, em arranjo fatorial $2 \times 2 \times 3$, sendo: 2 embalagens (permeável e impermeável ao vapor d'água - saco de papel e vidro, respectivamente); 2 ambientes (ambiente de laboratório, temperatura média $27^{\circ} \mathrm{C}$ e umidade relativa $85 \%$; câmara fria, temperatura de $8^{\circ} \mathrm{C}$ e 
umidade relativa $55 \%$ ) e 3 períodos de armazenamento (2, 4 e 6 meses).

$\mathrm{Na}$ ocasião da instalação do experimento foram determinados o teor de água, a viabilidade inicial e o peso de mil sementes, de acordo com prescrições de Brasil (1992).

Por não existir na literatura informações concernentes à tolerância ao processo de dessecação das sementes, estas foram submetidas ao armazenamento sem que se procedesse nenhum método de secagem.

Os parâmetros avaliados durante o período de armazenamento foram:

- Teor de água: utilizou-se 2 repetições de 20 sementes e o teste foi conduzido de acordo com as Regras para análise de sementes (Brasil, 1992) pelo método de estufa a $105^{\circ} \mathrm{C}$ $\pm 3^{\circ} \mathrm{C}$, durante 24 horas.

- Germinação: utilizou-se 4 repetições de 25 sementes para cada tratamento, semeadas em substrato areia lavada, mantidas em câmara de germinação a temperatura constante de $30^{\circ} \mathrm{C}$ e a última contagem foi realizada 30 dias após a semeadura.

- Índice de Velocidade de Emergência (IVE): obtido a partir dos dados do teste de germinação, empregando a metodologia descrita por Popinigis (1985).

- Comprimento de plântulas: a partir do teste de germinação, obteve-se a média do comprimento da parte aérea de dez plântulas normais, escolhidas ao acaso, por tratamento/repetição.

\section{RESULTADOS E DISCUSSÃO}

As sementes utilizadas neste estudo foram coletadas no chão, sendo que no período de dispersão, observou-se a presença de tucanos (Ramphastos spp.), os quais abriam os frutos, ingeriam o arilo e regurgitavam as sementes. Segundo Motta Junior \& Lombardi (1990), o tucanuçu (Ramphastos toco) e a gralha do campo (Cyanocorax cristatellus), também alimentam-se do arilo e regurgitam as sementes de Copaifera langsdorffii.

No periodo da dispersão, o peso de mil sementes foi de $1.416,7 \mathrm{~g}$ e o teor de água de $34 \%$. Para esta mesma espécie, Alencar (1981) e Embrapa (1991) encontraram peso de mil sementes de $1.538 \mathrm{~g}$ e $1.570 \mathrm{~g}$, respectivamente. Com relação ao teor de água das sementes, o segundo autor cita o percentual de $46 \%$, enquanto que o primeiro não o mencionou. Por ocasião da coleta, as sementes apresentaram $94 \%$ de germinação, percentagem esta superior àquelas encontradas por Alencar (1981), Façanha \& Varela (1986/87) e Embrapa (1991).

Verificou-se que a embalagem exerceu influência significativa $(\mathrm{P}<0,05)$ sobre o teor de água das sementes, durante o período de armazenamento. As sementes acondicionadas em embalagem permeável apresentaram redução considerável no teor de água, quando comparadas com o teor de água inicial (34\%), independente do ambiente em que foram mantidas (Fig. 1). Essa redução deve-se ao tipo de embalagem utilizada, pois a mesma permite uma 


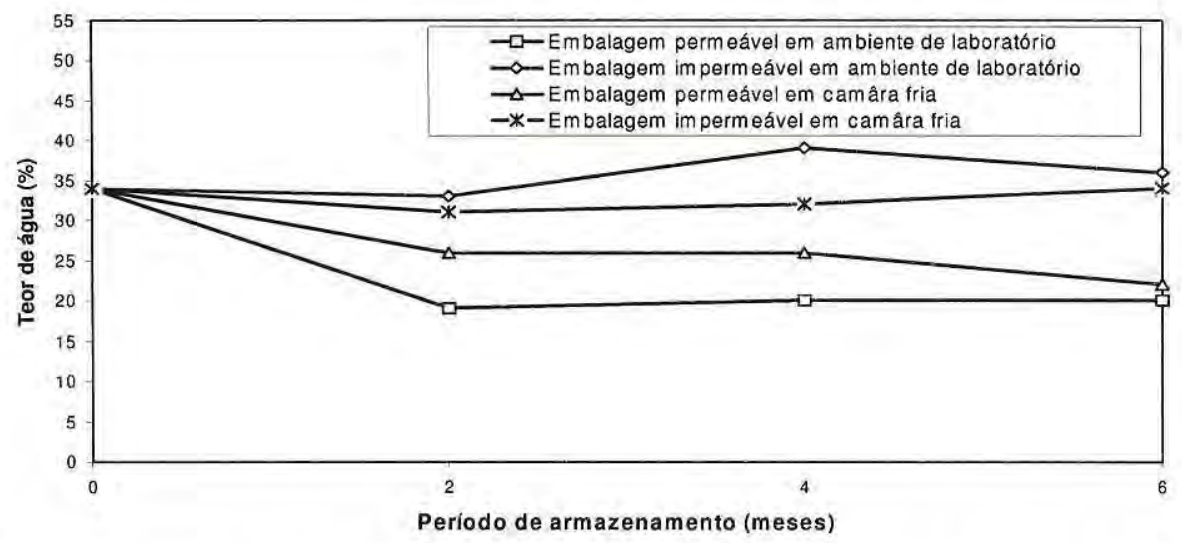

Figura 1. Teor de água de sementes de Copaifera multijuga submetidas a diferentes condições de armazenamento.

livre troca de vapor d'água entre as sementes e o ambiente circundante.

As sementes mantidas em ambiente de laboratório, acondicionadas em embalagem impermeável, apresentaram maior teor de água que aquelas armazenadas em câmara fria. Isso ocorreu, provavelmente devido a maior taxa respiratória das sementes mantidas em ambiente com maior temperatura (laboratório), proporcionando maior liberação de água, aumentando sobremaneira a umidade relativa do ar no interior da embalagem. Consequentemente a esse fato, a atividade de microrganismos que encontram-se associados às sementes também é acelerada, de modo quẻ o processo de deterioração destas pode ser ainda mais rápido nesse tipo de embalagem. Popinigis (1985) relata que $o$ alto teor de água é a maior causa de deterioração da semente armazenada.

A partir do segundo mês de armazenamento, independente do ambiente, verificou-se a influência da embalagem sobre a germinação, sendo constatada a superioridade da embalagem permeável na manutenção da viabilidade das sementes (Fig. 2). Leão (1984) constatou que a embalagem permeável mostrou-se mais eficiente que a semi-permeável na conservação da viabilidade das sementes de morototó (Didymopanax morototoni). No entanto, Façanha \& Varela (1986/87) concluiram que sementes de $C$. multijuga acondicionadas em embalagem impermeável, em geladeira, apresentaram queda no poder germinativo, em média $23 \%$, após 30 dias de armazenamento.

A partir do quarto mês de armazenamento, o ambiente passou a exercer maior influência que a embalagem sobre a conservação das sementes, de modo que aquelas mantidas na câmara fria apresentaram os maiores percentuais de germinação, 
sobretudo às acondicionadas em embalagem permeável. Por outro lado, as sementes mantidas em ambiente de laboratório e acondicionadas em embalagem impermeável, já haviam perdido completamente a sua viabilidade. Estes resultados, quanto as embalagens e ambientes de armazenamento, assemelham-se aos obtidos por Varela \& Barbosa (1986/ 87) para sementes de cedrorana (Cedrelinga catenaeformis Ducke).

Vale ressaltar que, mesmo quando mantidas sob as melhores condições, a partir do sexto mês de armazenamento, as sementes de $C$. multijuga tiveram sua viabilidade reduzida drasticamente, quando comparada com a percentagem de germinação inicial, alcançando valor inferior a 50\% (Fig. 2).

Quando armazenadas em ambiente de laboratório, as sementes acondicionadas em embalagem permeável, mantiveram maiores indices de vigor que aquelas acondicionadas em embalagem impermeável, conforme verificado no Índice de Velocidade de Emergência (Fig. 3). Pode-se constatar, por meio do IVE, que o ambiente exerceu maior influência que a embalagem sobre a conservação das sementes, de modo que a partir do quarto mês de armazenamento, as sementes mantidas em ambiente de laboratório, independente da embalagem, tiveram seu vigor reduzido significativamente $(\mathrm{P}<0,01)$. Entretanto, para aquelas mantidas em câmara fria, este fato só tornou-se relevante no sexto mês de armazenamento, sendo que as sementes acondicionadas em embalagem impermeável apresentaram redução mais drástica no vigor.

O teste de vigor baseado no comprimento da parte aérea de plântulas não mostrou-se eficiente em detectar diferenças entre as

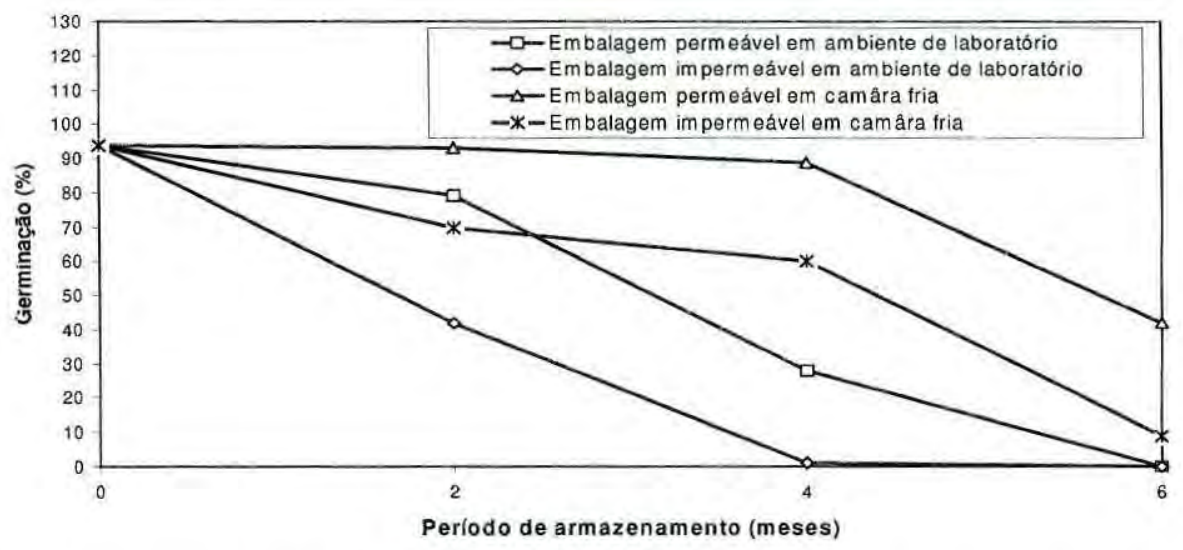

Figura 2. Germinação de sementes de Copaifera multijuga submetidas a diferentes condições de armazenamento 


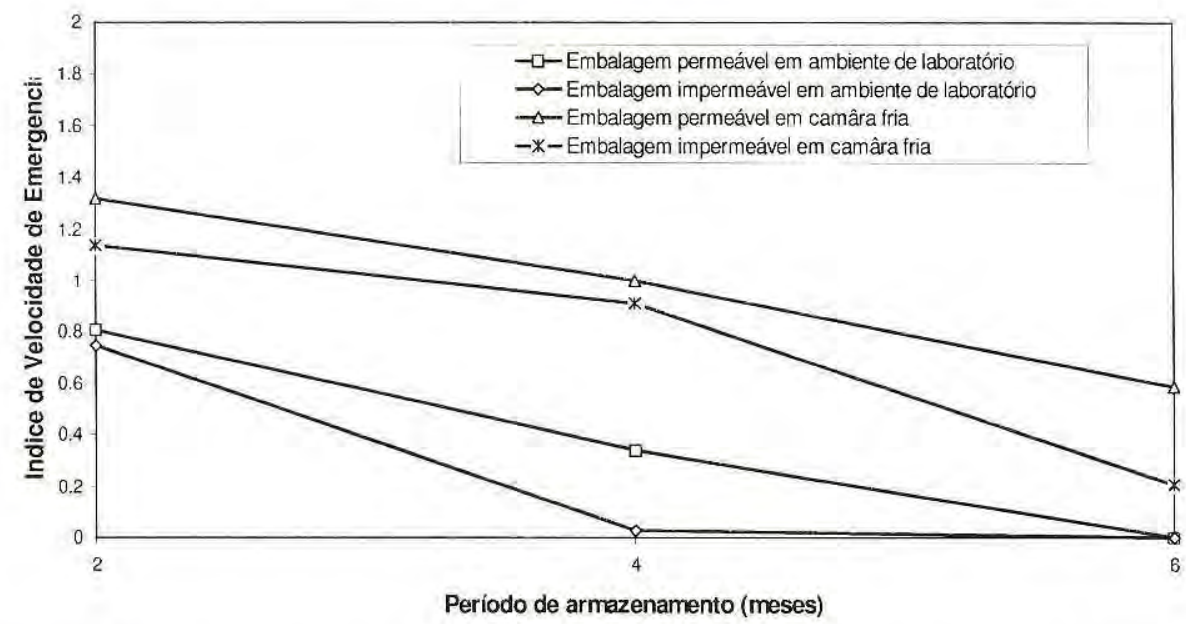

Figura 3. Vigor de sementes de Copaifera multijuga avaliado por meio do Índice de Velocidade de Emergência (IVE) quando submetidas a diferentes condições de armazenamento.

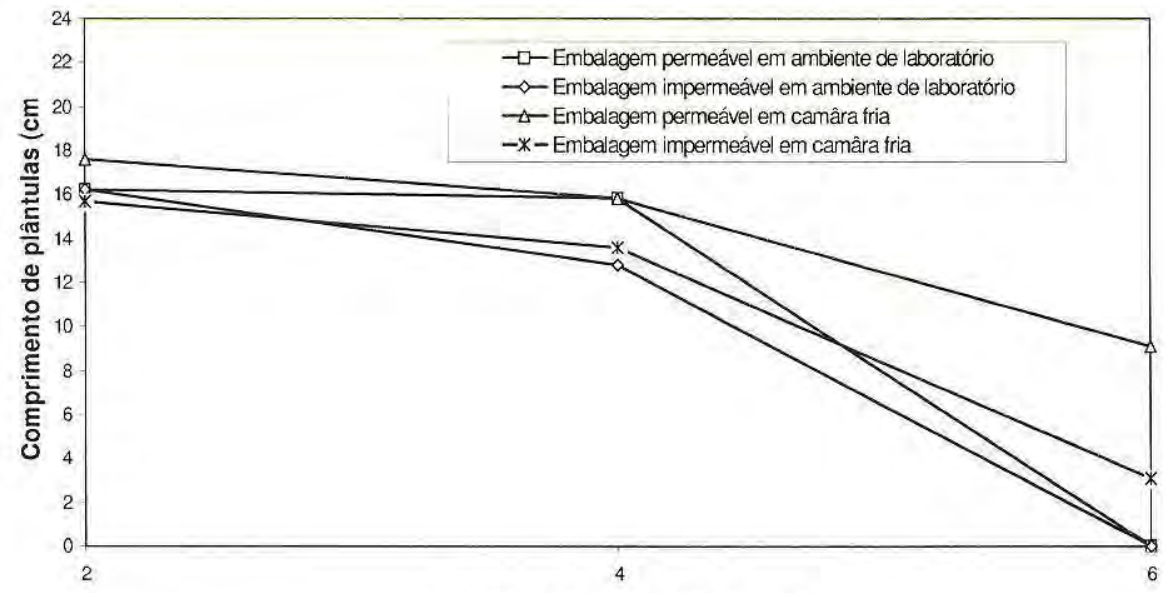

Periodo de armazenamento (meses)

Figura 4. Vigor de sementes de Copaifera multijuga avaliado por meio do teste de comprimento de plântula quando submetidas a diferentes condições de armazenamento.

embalagens no ambiente de comprimento de plântulas mostrou-se laboratório (Figura 4). Entretanto, no sensível, ao ponto de detectar ambiente de câmara fria, onde obteve- diferenças significativas $(\mathrm{P}<0,01)$ ense uma maior incidência de plântulas tre as embalagens no sexto mês de normais, com percentual de $39 \%$, armazenamento, indicando a observou-se que o teste de superioridade da embalagem 
permeável.

\section{CONCLUSÕES}

Em ambiente de laboratório ocorre redução drástica na viabilidade de sementes de Copaifera multijuga, após dois meses de armazenamento.

A embalagem permeável é eficiente na conservação de sementes de C. multijuga por um período de quatro meses em câmara fria.

\section{Bibliografia citada}

Albuquerque, J.M. de Pe. 1989. Plantas medicinais de uso popular. Associação Brasileira de Educação Agrícola Superior/ Ministério da Educação e Cultura (ABEAS/ MEC), Brasilia, Distrito Federal. 96p.

Alencar, J, da C. 1981. Estudos silviculturais de uma população natural de Copaifera multijuga Hayne - Leguminosae, na Amazônia Central. 1- Germinação. Acta Amazonica, 11(1):3-11.

Brasil. 1992. Regras para Análise de Sementes. Ministério da Agricultura e Reforma Agrária, Brasília, Distrito Federal. 365p.

Embrapa - CPATU. 1991. Encontro sobre pesquisa florestal na região do Tapajós. 1990, Santarém, PA. (Embrapa - CPATU. Documentos, 55). Embrapa-CPATU, Belém, Pará. 69p.

Façanha, J.G.V.; Varela, V.P. 1986/1987. Resultados preliminares de estudos sobre a conservação e composição bioquímica de sementes de copaiba (Copaifera multijuga Hayne) - Leguminosae. Acta Amazonica, 16/17:377-382.
Leão, N.V.M. 1984. Conservação de sementes de morototó (Didymopanax morototoni (Aublet) Decne.). (Embrapa-CPATU. Boletim de Pesquisa, 64). EmbrapaCPATU, Belém, Pará. 16p.

Loureiro, A.A.; Silva, M.F. da; Alencar, J. da C. 1979. Essências Madeireiras da Amazônia. Vol.1. Instituto Nacional de Pesquisas da Amazônia (INPA), Manaus, Amazonas. 245p.

Motta Junior, J.C.; Lombardi, J.A. 1990. Aves como agentes dispersores de copaíba (Copaifera langsdorffii, Caesalpinaceae) em São Carlos, Estado de São Paulo. Ararajuba, 1:105-106.

Parrotta, J.A.; Francis, J.K.; Almeida, R.R. de. 1995. Trees of the Tapajós. A photographic field guide. International Institute of Tropical Forestry, USDA Forest Service, Rio Piedras, Puerto Rico-USA e Instituto Brasileiro do Meio Ambiente e dos Recursos Naturais Renováveis (IBAMA), Santarém, Pará, Brasil. 371p.

Popinigis, F. 1985. Fisiologia da Semente. Associação Brasileira de Educação Agrícola Superior/ Ministério da Educação e Cultura (ABEAS/MEC), Brasília, Distrito Federal. 289p.

SEBRAE/AM; IMA/AM. 1993. Diagnóstico do subsetor madeireiro do Estado do Amazonas, Série Estudos Setoriais. Serviço Brasileiro de Apoio às Micro e Pequenas Empresas (SEBRAE), Manaus, Amazonas. 76p.

Varela, V.P.; Barbosa, A.P. 1986/1987. Conservação de sementes de cedrorana (Cedrelinga catenaeformis Ducke) - Leguminosae. Acta Amazonica, 16/17:549-556. 